\title{
Endoscopic vein harvesting
}

\author{
Enoch Akowuah $^{1}$, Daniel Burns ${ }^{2}$, Joseph Zacharias ${ }^{3}$, Bilal H. Kirmani ${ }^{2} \wedge$ \\ ${ }^{1}$ Department of Cardiac Surgery, James Cook University Hospital, South Tees NHS, Foundation Trust, Middlesbrough, UK; ${ }^{2}$ Department of \\ Cardiac Surgery, Liverpool Heart and Chest Hospital, Liverpool, UK; ${ }^{3}$ Department of Cardiothoracic Surgery, Blackpool Victoria Hospital, \\ Blackpool, UK \\ Contributions: (I) Conception and design: E Akowuah, BH Kirmani; (II) Administrative support: None; (III) Provision of study materials or patients: \\ None; (IV) Collection and assembly of data: E Akowuah, D Burns, BH Kirmani; (V) Data analysis and interpretation: None; (VI) Manuscript writing: \\ All authors; (VII) Final approval of manuscript: All authors. \\ Correspondence to: Bilal Kirmani. Liverpool Heart \& Chest Hospital, Thomas Drive, Liverpool, L14 3PE, UK. Email: bil.kirmani@lhch.nhs.uk.
}

\begin{abstract}
Coronary artery bypass grafting is the most common cardiac surgical procedure performed worldwide and the long saphenous vein the most common conduit for this. When performed as an open vein harvest $(\mathrm{OVH})$, the incision on each leg can be up to $85 \mathrm{~cm}$ long, making it the longest incision of any routine procedure. This confers a high degree of morbidity to the procedure. Endoscopic vein harvest (EVH) methods were popularised over two decades ago, demonstrating significant benefits over OVH in terms of leg wound complications including surgical site infections. They also appeared to hasten return to usual activities and wound healing and became popular particularly in North America. Subgroup analyses of two trials designed for other purposes created a period of uncertainty between 2009-2013 while the impact of endoscopic vein harvesting on vein graft patency and major adverse cardiac events was scrutinised. Large observational studies debunked the findings of increased mortality in the short-term, allowing practitioners and governing bodies to regain some confidence in the procedure. A well designed, adequately powered, randomised controlled trial published in 2019 also definitively demonstrated that there was no increase in death, myocardial infarction or repeat revascularisation with endoscopic vein harvest. Endoscopic vein harvest is a Class IIa indication in European Association of Cardio-Thoracic Surgery (EACTS) and a Class I indication in International Society of Minimally Invasive Cardiac Surgery (ISMICS) guidelines.
\end{abstract}

Keywords: Coronary artery bypass; minimally invasive; conduit; saphenous vein; endoscopic

Submitted May 01, 2020. Accepted for publication Sep 18, 2020.

doi: $10.21037 /$ jtd-20-1819

View this article at: http://dx.doi.org/10.21037/jtd-20-1819

\section{Introduction}

Coronary artery bypass grafting is the most common cardiac surgical procedure performed worldwide and is the definitive treatment for ischaemic heart disease. Where medical management and percutaneous coronary interventions can alleviate symptoms of stable angina, bypass grafting is unique in that it also confers a prognostic advantage in most patients. This benefit is thought to be related to the anastomosis of the left internal mammary artery to the left anterior descending coronary artery (LIMA-LAD) (1). The use of the long saphenous vein predominates worldwide for the remainder of nonLIMA-LAD bypasses, despite the fact that arterial conduit demonstrates three- to four-fold improvements in long term patency compared to venous conduit (2). A multitude of factors related to patient, surgeon and hospital environments dictate the long-standing popularity of the long saphenous vein. The right internal mammary artery,

$\wedge$ ORCID: 0000-0002-5028-5505. 
which may be the second most reliable conduit after the left internal mammary, has seen poor adoption because of the increased risk of sternal dehiscence and deep sternal wound infection with use of bilateral internal mammary arteries. The additional surgical time by not having two concurrent conduits being harvested is also thought to limit greater use of two mammary arteries. The radial artery has been demonstrated to approach the patency of the right internal mammary artery without sacrificing sternal stability, but is prone to spasm, especially where competitive flow exists. Moreover, it might not be suitable when the coronary artery is not severely stenosed (90\%) and may be more prone to late graft failure in such circumstances (3). Its use is therefore limited to vessels with tight proximal stenoses, and, due to its limited length, may not be suitable for all target vessels. A trend towards radial artery catheterisation for coronary angiography, percutaneous intervention and arteriovenous fistula formation for haemodialysis may also limit the use of the radial as conduit (4). The right gastroepiploic artery (GEA) is an effective conduit with excellent patency rates, and is popular in Asia where surgeons tend to be more familiar with the harvesting and management of this conduit, but it has never been widely used in Europe or the Americas.

Consequently, the long saphenous vein, which is abundant and technically undemanding to harvest, is the preferred second conduit for the majority (86\%) of surgeons (5). Harvesting can be performed without the use of specialist equipment and is the conduit of choice in emergencies where revascularisation is required expeditiously.

\section{Early history of endoscopic vein harvest}

The full saphenectomy wound is the longest used in any surgery, with harvest lengths up to $85 \mathrm{~cm}$ (6). This can confer significant morbidity to patients, affecting a quarter to a third of patients who have an open surgical harvest and adding substantially to the cost of wound care in the post-operative period $(7,8)$. In the mid-nineties, Lumsden et al. described the first steps towards reducing the impact of the saphenectomy wound with endoscopic vein harvest (EVH) (9). Although the procedure took longer than conventional harvest, results were promising with low complication rates (especially considering the learning curve associated with the new technique) and excellent patient feedback. Within 2 years, the procedure was three times as fast (10) and reduced leg wound infections by $80 \%$ (11).
Patients with minimally invasive vein harvest also went home four days sooner than patients with open harvest (12). Attempts to perform less-invasive saphenectomy without the use of specialised technology were less effective: the "bridging" technique took longer to open, harvest and close than EVH (13) and time to ambulation and length of hospital stay were still superior with endoscopic techniques (14). Even in patients at high risk of leg wound complications, the EVH procedure was seen to produce excellent results, negating some of the risk factors $(15,16)$ and one study even determined that the only risk factor for leg wound complications was the open vein harvest (OVH) technique (17). Five-year event-free survival was found in a small randomised controlled trial to be no different with EVH compared with open vein harvest (18).

By 2005, it was the consensus of the International Society of Minimally Invasive Cardio-Thoracic Surgery (ISMICS) that $\mathrm{EVH}$ should be the standard of care for saphenous vein harvest, citing it as a Class I, Level B recommendation (19). The first systematic review and comprehensive metaanalysis on EVH demonstrated that it significantly improved wound infections, wound complications, surgical reintervention rates, hospital length of stay and readmission rates (20). This was at the cost of an additional 15 minutes in theatre. Uptake was prompt, especially in North America where $70 \%$ of vein harvest was performed by EVH by 2008, with an apparent strong patient and physician preference for "keyhole" techniques.

\section{EVH graft patency and clinical outcomes}

In 2009, a subgroup analysis of the PREVENT IV trial implied an increased rate of vein graft failure, defined as stenosis of $\geq 75 \%$, when conduit was harvested endoscopically (21). At 12 to 18 months following bypass grafting, $46.7 \%$ of EVH compared to $38.0 \%$ of open vein harvest had failed. At three years, this translated to an adjusted hazard ratio of 1.22 (95\% CI: 1.01-1.47) for death, myocardial infarction or repeat revascularisation. The hazard ratio for death alone was 1.52 (95\% CI: 1.13-2.04). In the United Kingdom, this led to the National Institute for Clinical Excellence (NICE) making immediate recommendations that patients should only be offered $\mathrm{EVH}$ in units already offering the service, and only then provided specific consent was sought from patients, informing them of the increased risks of graft failure and death. Two cohort studies from established EVH centres were quick to demonstrate that there was no evidence of increased 
mortality, repeat revascularisation or return of symptoms in their populations $(22,23)$.

A second subgroup analysis, of the Randomized On/Off Bypass (ROOBY) Trial, also suggested a higher vein graft occlusion rate with $\mathrm{EVH}$ at 1 year $[25.5 \%$ vs. $14.8 \%$, relative risk 1.14 (95\% CI: 1.09-1.20)], associated with a higher repeat revascularisation rate (6.7\% vs. 3.4\%) (24). Critics noted that the trials, both sub studies of RCTs designed to answer different clinical questions, were never intended to examine the effects of EVH on graft patency and major clinical outcomes, and had been conducted at a time early in the national uptake of endoscopic techniques (25).

Real world studies refuting the findings of the both the PREVENT IV and ROOBY subgroup analyses continued to accumulate. A retrospective, non-randomised study of 8,542 patients from New England demonstrated a mortality benefit to patients undergoing EVH (26). A large population study of EVH examining nearly a quarter of a million patients also showed no difference in long-term survival (27). The size of this study would go on to weight the results of a number of subsequent systematic reviews in support of its findings.

One such study, a 2013 meta-analysis, was relied upon by NICE to confirm the long-term safety of EVH (28). The median follow-up in the trials included in this review was 22.5 months and demonstrated no increased risk of death in the EVH group to that time point. There was a trend towards increased revascularisation in the $\mathrm{EVH}$ in that period (standardised risk ratio 1.16, 95\% CI: 0.99-1.36, $\mathrm{P}=0.06$ ), but did not reach statistical significance.

Two small trials randomising patients to either endoscopic or open vein harvest (rather than subgroup analyses of trials randomising to other treatments) have been performed in which graft patency was later assessed. Yun et al. randomised 200 patients and undertook angiography at 6 months. Occlusion rates were $21.7 \%$ in the EVH group and $17.6 \%$ in $\mathrm{OVH}$ group. Logistic regression did not identify endoscopic vein harvest to be a risk factor for vein failure (29). A Danish group since published long-term results of their randomised controlled trial, with a median follow-up of 6.3 years, but had only 66 patients in the endoscopic vein harvest arm of the study. They found, in a sample of the study group, that EVH was associated with a reduced graft patency ( $42 \%$ vs. $6 \%$ ) although this was not related to an increase in angina, myocardial infarction or mortality (30). A recent patient-level data meta-analysis using only EVH from experienced centres identified that endoscopic harvest might even reduce the risk of graft failure (31).

In response to the overwhelming evidence that $\mathrm{EVH}$ was not associated with increased mid-term mortality or revascularisation, the National Institute for Health and Care Excellence (NICE) published guidance in 2014 supporting the use of endoscopic vein harvest (32). Despite this change in the guidance, uptake of EVH in the UK has remained low with less than $20-30 \%$ of patients undergoing $\mathrm{EVH}$. This is because of persistent concerns about vein graft patency.

Several attempts have been made to synthesise the existing studies on endoscopic vein harvest mid-term outcomes. The quality of the source data is invariably heterogenous and authors of different meta-analyses have differed in which material to aggregate $(28,33,34)$. More contemporaneous studies where operators have accumulated experience and are using later generation devices seem to indicate superior patency and mid-term outcomes (35). The learning curve effect is therefore important to consider when comparing EVH with the open technique (36).

The REGROUP randomised controlled trial (37) was the only large, multi-centre study adequately powered to confidently address concerns about the mid-term clinical outcomes with endoscopic vein harvest. A total of 1,150 patients were followed up for 2.78 years and the primary composite endpoint (major adverse cardiac events, nonfatal myocardial infarction and repeat revascularisation) occurred in $15.5 \%$ in the open harvest group and $13.9 \%$ in the endoscopic vein harvest group (hazard ratio 1.12, 95\% CI: $0.83-1.51)$. This study pre-specified a minimum level of expertise from the endoscopic vein harvesters defined as $>100$ harvests performed in an $\mathrm{EVH}$ program of at least 2 years, with $<5 \%$ conversion to open. The patients were well matched for baseline characteristics, including coronary disease burden with equivalent SYNTAX scores, addressing many of the concerns raised by previous studies. It was felt that graft patency was an imperfect surrogate for clinical events and that the essential safety concerns about EVH had been answered.

Nonetheless, the authors emphasise that the exclusion of off-pump coronary artery bypass grafting (by design) and non-touch open saphenous vein harvest (by coincidence) may limit the application of these findings.

\section{Benefits and risks}

The in-hospital advantages on pain, wound infection and hospital length of stay of EVH have been well established 
Table 1 Benefits and risks of endoscopic vein harvest from four meta-analyses (28,33-35)

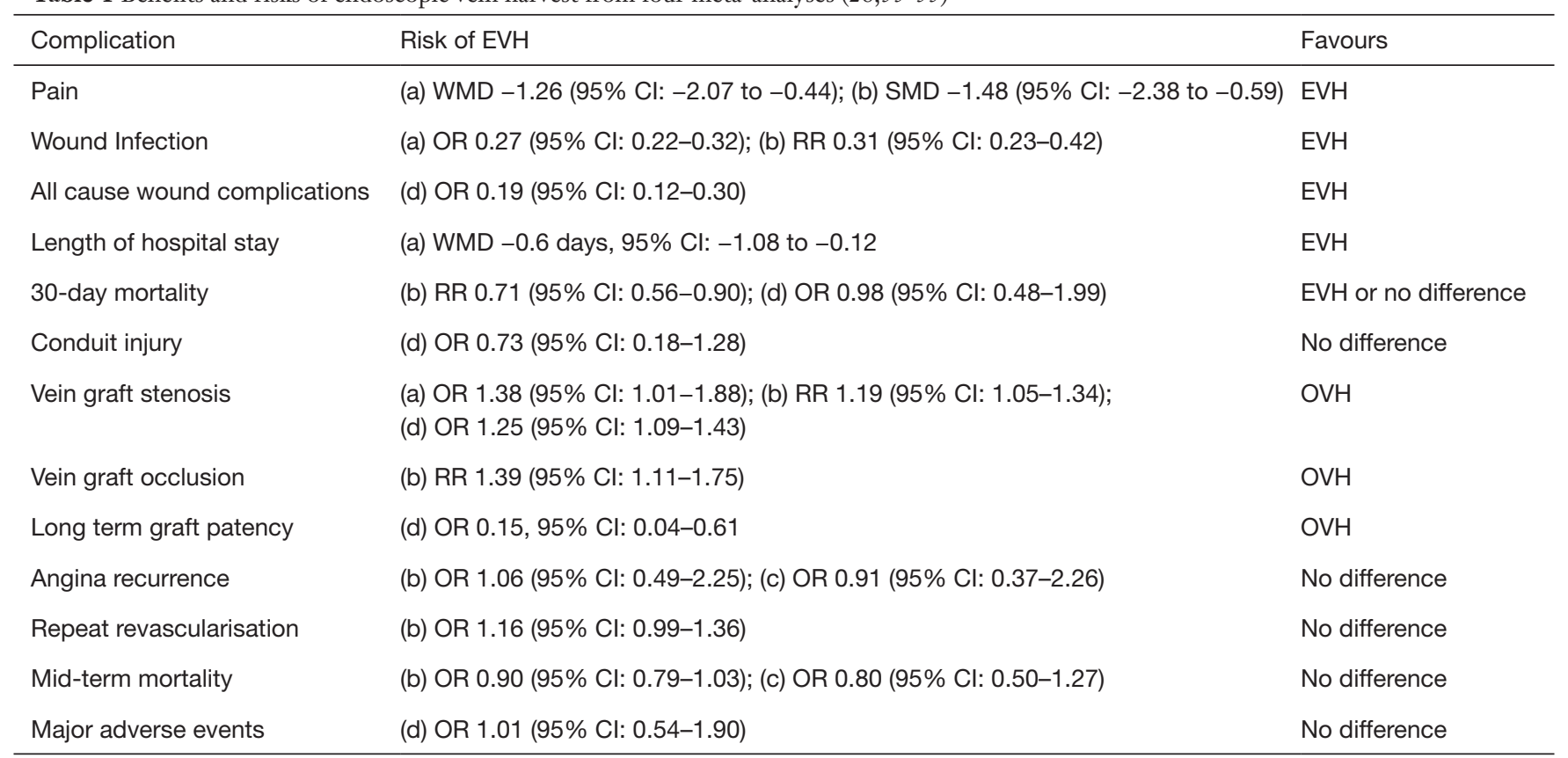

$\mathrm{EVH}$, endoscopic vein harvest; OVH, open vein harvest; WMD, weighted mean difference; Cl, confidence interval; OR, odds ratio; RR, relative risk; NA, not assessed. (a) Deppe 2013 (34), (b) Sastry 2013 (28), (c) Kodia 2018 (33), (d) Li 2019 (35).

through multiple randomised and observational studies. Meta-analysis shows a nearly five times reduction in the incidence of infections (38). Long term follow-up has indicated a reduced vein graft patency but apparently with no resulting effects on angina recurrence, repeat revascularisation, major adverse cardiac events or mortality (39). These findings have been aggregated in a number of systematic reviews, summarised in Table 1.

Following discharge, return to normal activities of daily living is much quicker with EVH (median 6, range: 2-30 weeks) compared to OVH (median 9, range: 2-50 weeks) and even at two years follow-up, quality of life scores for physical health are higher with endoscopic vein harvest $(45.3 \pm 10.2$ vs. $40.7 \pm 11.0)$ (36).

\section{Surgical technique}

\section{Vein mapping}

The use of vascular ultrasound to delineate subcutaneous anatomy prior to skin incision has been described since the early period of EVH (40). Pre-operative conduit planning has been shown to reduce unnecessary incisions even for open vein harvest and thus expedites surgical conduit harvest times (41). Prior to endoscopic vein harvest, therefore, ultrasound assessment of the long saphenous vein to assess for calibre, varicosities, side-branches and surface anatomy is normally undertaken (Figure 1). This is increasingly utilised for both endoscopic and open vein harvest. Having identified the vessel along its course, the leg is prepared and draped as for open harvest, which remains the bailout.

\section{Endoscopic vein harvest}

A 2-3 cm transverse incision is made over the vessel at the knee and blunt dissection employed to identify the vein. Prior to introduction of the instrument port, 5,000 U unfractionated heparin is given via the central line to reduce the risk of thrombosis during harvest. Several manufacturers offer equipment for EVH (Figure 2), with small differences in the methodology for harvest, but most follow the same principles. The dissection tunnel is insufflated with $\mathrm{CO}_{2}$, infused via the instrument port at a rate of $3 \mathrm{~L} / \mathrm{min}$ (Figure 3). This creates a potential space in which the working instruments can be manipulated around the vein, and can be either a closed or open tunnel depending on the device used and whether the inflatable cuff on the working port is engaged. A $10 \mathrm{~mm} 0^{\circ}$ camera is mounted with a blunt 

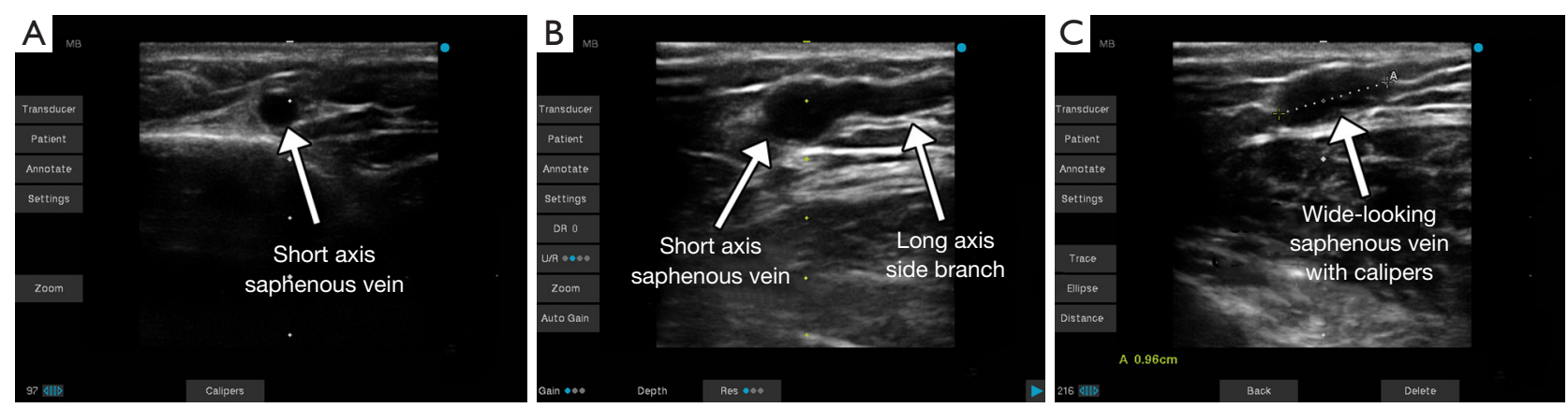

Figure 1 Images from pre-operative ultrasound scanning of long saphenous vein. (A) The vein in short axis; (B) a side branch appearing in long axis; (C) a vein in short axis measuring $0.96 \mathrm{~cm}$ with calipers-this could be a varicosity, a patulous vein or a confluence of vessels.

A

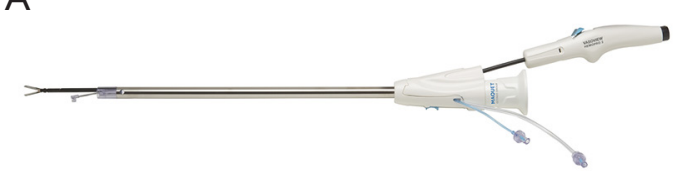

B

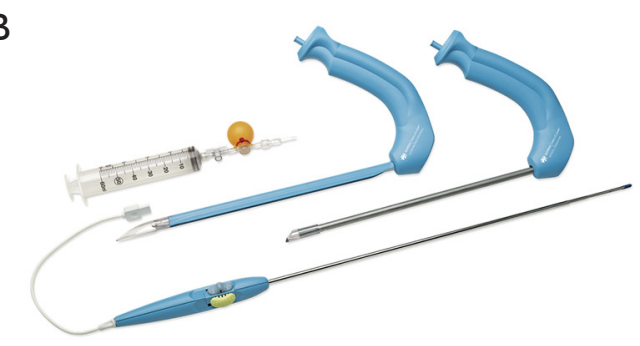

C

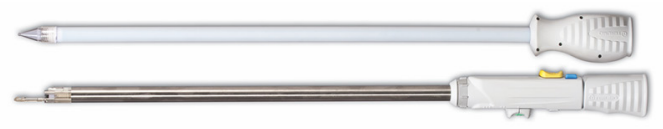

Figure 2 Endoscopic vein harvesting equipment from various manufacturers. (A) VasoView Hemopro 2 (Getinge AB, Sweden) (Image ${ }^{\oplus}$ Getinge, used with permission); (B) Vascuclear (LivaNova, London, UK) (Image ${ }^{\odot}$ LivaNova, used with permission); (C) VirtuoSaph ${ }^{\circledast}$ Plus (Terumo, Tokyo, Japan) $\left(\right.$ Image $^{\oplus}$ Terumo Cardiovascular, used with permission).

conical tip through which the operating field is visualised and which also serves as a dissecting tool with which to push tissues off the vein with low risk of perforating the vessel or avulsing side branches. The position of the dissecting tool in relation to the surface anatomy is noted by palpation

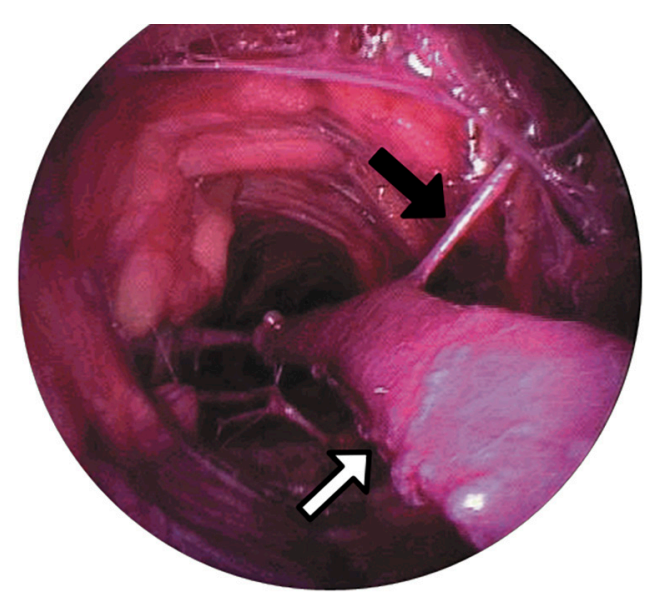

Figure $3 \mathrm{~A}$ view through an endoscope at the $\mathrm{CO}_{2}$-insufflated dissection tunnel for the long saphenous vein (white arrow). A side branch can be seen extending superficially (black arrow). (Image ${ }^{\odot}$ Getinge).

of the conical tip and transillumination through the skin. Once the vein has been systematically dissected anteriorally, posteriorally, laterally and medially, the dissecting tip is exchanged for a clamp with a cautery energy source. The vessel is retracted and side branches cauterised and divided as far from the saphenous vein as possible (Figure 4). Once these are all been divided, a stab incision at the groin or medial malleolus allows a vascular forceps to clamp and divide the far-end (either proximal or distal to the knee) of the vein prior to withdrawing the conduit by gentle traction at the knee. The free ends of the vessel can be ligated prior to wound closure and application of a compression bandage.

During this procedure, there are several potential sources of trauma to the long saphenous vein. If the blunt conical dissecting tool is not in the correct tissue plane, 


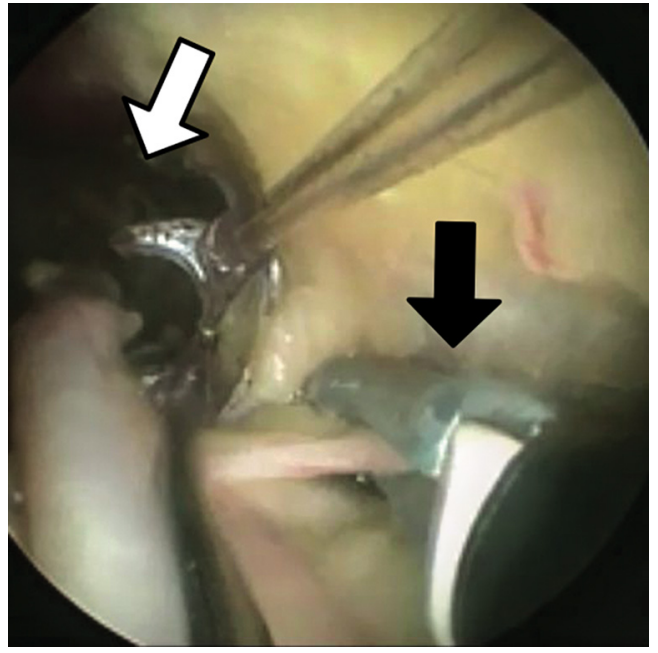

Figure 4 The long saphenous vein is retracted using the device $\mathrm{C}$-arm distally in the tunnel (white arrow), while a side branch is cauterised and transected (black arrow). (Image ${ }^{\odot}$ Getinge).

the adventitia of the vein can be stripped, or the vein partially or completely perforated. Small side branches may be avulsed instead of pushed aside. The ligating energy source may generate thermal damage to the vessel, or the side branches may be divided too close to the vessel. Additionally, the retracting loop or arm of the device may over-tension the vein, affecting the endothelial integrity. Some of these injuries may be apparent as macroscopic tears or haematomas in the vessel which can be excluded, but occult injury affecting the vasoactive properties of the vein may present at a later stage with patency issues.

\section{Economic impact of endoscopic vein harvest}

In lower-extremity bypass, EVH leads to a significant costbenefit, derived from reduction in wound complications, improvements in ambulation and earlier discharge (42).

If including the costs of training and the effects of the learning curve, endoscopic vein harvest for coronary artery bypass does not initially look economically viable (43). Excluding the capital costs of the learning curve, however, the first randomised controlled trial to look at the economic impact of endoscopic versus open vein harvest found no statistically significant difference in the costs (44) - but the technique at the time was in its infancy and contributed an additional 72 minutes to the operating time. With skilled operators now harvesting as fast as (or faster than) the open technique, this may now favour endoscopic vein harvesting.

The only systematic review of economic viability demonstrated a benefit to performing EVH not only in hospital costs, but also in quality-adjusted life years for the patient (45). As expected, the benefit of EVH diminishes as the length of the incision spared is reduced (43), so saphenous vein harvest for single lengths would not contribute to savings made elsewhere. The only British cost-benefit analysis of EVH demonstrated substantial savings in high risk patients made from avoidance of outpatient wound care (8). In a cohort of 100 patients, the overall cost saving by performing EVH was $£ 42,778$.

\section{Sequalae of endoscopic vein harvesting}

\section{Macroscopic injury}

During the learning curve, macroscopic traction, perforation and thermal injuries can be increased during endoscopic vein harvest. With increasing experience, these should reduce. Meta-analysis has shown that there is no difference in gross conduit injury (35).

\section{Microscopic injury}

Some early studies found no statistically significant difference in the histological appearances of vein harvested endoscopically versus that taken from a longitudinal open incision (46-48). One even suggested that the endoscopic technique had benefits on the intimal integrity (49). The single centre, randomised, controlled Vein Integrity and Clinical Outcomes (VICO) trial (50) looked at endothelial integrity, muscular morphology and major adverse clinical outcomes at 48 months following closed-and opentunnel EVH and OVH. Open vein harvest, utilising a notouch method and preserving adventitia and perivascular fat, demonstrated superior endothelial integrity and less muscular stretching and hypertrophy in the open vein harvest. This did not, however, translate to clinical differences in outcome at 4 years follow up.

Rousou et al. also suggested that even in the absence of histological changes, there was an increased rate of functional endothelial changes with EVH (51). The authors hypothesised that there might be further long-term issues with patency. Caveats to this research were that the endoscopic vein harvest experience in this institution was not described, raising the possibility of an effect of the early part of the learning curve. The results were not replicated 
by another group (52). Subsequent work confirmed that early harvests are subject to more surgical trauma than those taken by experienced operators (53). Although endoscopic vein harvest is associated with more endothelial stretch, open vein harvest has more endothelial detachment and EVH has overall better histologically preserved endothelium (54).

\section{Discussion}

A number of interrelated factors determine the short- and long- term patency of coronary artery bypass grafts. Patient factors such as coronary anatomy, extent of disease, distal runoff and co-morbid conditions such as renal impairment tend to be relatively fixed. Other comorbidities can be optimised by lifestyle or medication changes (e.g., diabetes, dyslipidaemia, smoking status). Surgical factors including use (or not) of the cardiopulmonary bypass machine, choice of conduit and surgeon experience may also be modifiable.

Some methods have been shown to significantly improve long term patency rates of the long saphenous vein, approaching those of arterial conduit (55). A no-touch technique, harvesting the saphenous vein with a fatty pedicle, respects the saphenous vein as more than just an inert tube and preserves its endocrine and vasoactive properties. This has been shown to substantially improve patency (56-58). Allied with transit-time flow measurements (55) to reduce early technical anastomotic failures and secondary prevention medications, saphenous vein graft patency can be excellent.

In practice, however, most open saphenous vein grafts harvests are still performed skeletonised without a no-touch technique (37) and intra-operative graft assessments are uncommon. This may impair the long-term patency-which is seldom assessed outside of clinical trials. Whereas the LIMA-LAD graft is thought to be singularly responsible for improved life expectancy following coronary artery bypass grafting, the effects of occluded grafts elsewhere on the heart is less clear. Few studies have examined the long-term clinical outcomes such as mortality, repeat revascularisation or symptom recurrence associated with graft occlusion, and systematic review indicates that the data is heterogenous and difficult to aggregate (59). The clinical effects of failing saphenous vein grafts in the context of patent LIMA-LAD, therefore, are difficult to know: studies may have been underpowered to detect small differences and many did not include angina recurrence as a late outcome. This is an outcome that is extremely important to patients.
The ESC/EACTS Guidelines on coronary revascularisation from 2018 recommend EVH (Class IIa recommendation, Level of Evidence A) as a means to reduce the incidence of wound complications (60). The same guidelines recommend that, where the open harvest method is employed, the no-touch technique should be considered (Class IIa, Level B). These recommendations, virtually the antithesis of each other in terms of their clinical priorities, typify the difficulty in balancing short- and long-term risks and benefits for patients.

\section{Conclusions}

Endoscopic vein harvest came under a pall nearly a decade ago, with concerns about mid-term patency and survival. There were no doubts about the short-term benefits of improved wound healing, faster return to activities of daily living and improved quality of life, and the technique appeared to be economically viable. It has now also been convincingly demonstrated that, in experienced hands, there is no increase in major adverse cardiac events or mortality and that the procedure is as safe in the mid- to long-term. Its impact on vein graft patency is yet to be accurately determined.

\section{Acknowledgments}

Funding: None.

\section{Footnote}

Provenance and Peer Review: This article was commissioned by the Guest Editors (Jason Ali and Yasir Abu-Omar) for the series "Minimally Invasive Cardiac Surgery" published in Journal of Thoracic Disease. The article has undergone external peer review.

Peer Review File: Available at http://dx.doi.org/10.21037/jtd20-1819

Conflicts of Interest: All authors have completed the ICMJE uniform disclosure form (available at http://dx.doi. org/10.21037/jtd-20-1819). The series "Minimally Invasive Cardiac Surgery" was commissioned by the editorial office without any funding or sponsorship. JZ reports proctoring and speaking fees from Edwards Lifesciences, Cryolife, and Abbott, and funded a clinical fellow post for 12 months from LSI solutions. The other authors have no conflicts of 
interest to declare.

Ethical Statement: The authors are accountable for all aspects of the work in ensuring that questions related to the accuracy or integrity of any part of the work are appropriately investigated and resolved.

Open Access Statement: This is an Open Access article distributed in accordance with the Creative Commons Attribution-NonCommercial-NoDerivs 4.0 International License (CC BY-NC-ND 4.0), which permits the noncommercial replication and distribution of the article with the strict proviso that no changes or edits are made and the original work is properly cited (including links to both the formal publication through the relevant DOI and the license). See: https://creativecommons.org/licenses/by-nc-nd/4.0/.

\section{References}

1. Loop FD, Lytle BW, Cosgrove DM, et al. Influence of the internal-mammary-artery graft on 10-year survival and other cardiac events. N Engl J Med 1986;314:1-6.

2. Benedetto U, Raja SG, Albanese A, et al. Searching for the second best graft for coronary artery bypass surgery: a network meta-analysis of randomized controlled trials. Eur J Cardiothorac Surg 2015;47:59-65.

3. Tatoulis J, Schwann TA. Long term outcomes of radial artery grafting in patients undergoing coronary artery bypass surgery. Ann Cardiothorac Surg 2018;7:636-43.

4. Mason PJ, Shah B, Tamis-Holland JE, et al. An Update on Radial Artery Access and Best Practices for Transradial Coronary Angiography and Intervention in Acute Coronary Syndrome: A Scientific Statement From the American Heart Association. Circ Cardiovasc Interv 2018;11:e000035.

5. Chikwe J, Sun E, Hannan EL, et al. Outcomes of Second Arterial Conduits in Patients Undergoing Multivessel Coronary Artery Bypass Graft Surgery. J Am Coll Cardiol 2019;74:2238-48.

6. Mandiye SS, Yadav A, Pathak S, et al. "Extended length" endoscopic harvest of the great saphenous vein for coronary artery bypass grafting. Indian J Thorac Cardiovasc Surg 2007;23:125-7.

7. Andreasen JJ, Nekrasas V, Dethlefsen C. Endoscopic vs open saphenous vein harvest for coronary artery bypass grafting: a prospective randomized trial. Eur J Cardiothorac Surg 2008;34:384-9.

8. Luckraz H, Kaur P, Bhabra M, et al. Endoscopic vein harvest in patients at high risk for leg wound complications: A cost-benefit analysis of an initial experience. Am J Infect Control 2016;44:1606-10.

9. Lumsden AB, Eaves FF 3rd, Ofenloch JC, et al. Subcutaneous, video-assisted saphenous vein harvest: report of the first 30 cases. Cardiovasc Surg 1996;4:771-6.

10. Davis Z, Jacobs HK, Zhang M, et al. Endoscopic vein harvest for coronary artery bypass grafting: technique and outcomes. J Thorac Cardiovasc Surg 1998;116:228-35.

11. Allen KB, Shaar CJ. Endoscopic saphenous vein harvesting. Ann Thorac Surg 1997;64:265-6.

12. Li CY, Lai ST, Yu TJ, et al. Endoscopic vein harvest for coronary artery bypass surgery. Zhonghua Yi Xue Za Zhi (Taipei) 1998;61:276-80.

13. Horvath KD, Gray D, Benton L, et al. Operative outcomes of minimally invasive saphenous vein harvest. Am J Surg 1998;175:391-5.

14. Patel AN, Hebeler RF, Hamman BL, et al. Prospective analysis of endoscopic vein harvesting. Am J Surg 2001;182:716-9.

15. Carrizo GJ, Livesay JJ, Luy L. Endoscopic harvesting of the greater saphenous vein for aortocoronary bypass grafting. Tex Heart Inst J 1999;26:120-3.

16. Allen KB, Heimansohn DA, Robison RJ, et al. Risk factors for leg wound complications following endoscopic versus traditional saphenous vein harvesting. Heart Surg Forum 2000;3:325-30.

17. Bitondo JM, Daggett WM, Torchiana DF, et al. Endoscopic versus open saphenous vein harvest: a comparison of postoperative wound complications. Ann Thorac Surg 2002;73:523-8.

18. Allen KB, Heimansohn DA, Robison RJ, et al. Influence of endoscopic versus traditional saphenectomy on event-free survival: five-year follow-up of a prospective randomized trial. Heart Surg Forum 2003;6:E143-5.

19. Allen K, Cheng D, Cohn W, et al. Endoscopic Vascular Harvest in Coronary Artery Bypass Grafting Surgery: A Consensus Statement of the International Society of Minimally Invasive Cardiothoracic Surgery (ISMICS) 2005. Innovations (Phila) 2005;1:51-60.

20. Cheng D, Allen K, Cohn W, et al. Endoscopic vascular harvest in coronary artery bypass grafting surgery: a meta-analysis of randomized trials and controlled trials. Innovations (Phila) 2005;1:61-74.

21. Magee MJ, Alexander JH, Hafley G, et al. Coronary Artery Bypass Graft Failure After On-Pump and Off-Pump Coronary Artery Bypass: Findings From PREVENT IV. Ann Thorac Surg 2008;85:494-9. 
22. Kirmani BH, Barnard JB, Mourad F, et al. Mid-term outcomes for Endoscopic versus Open Vein Harvest: a case control study. J Cardiothorac Surg 2010;5:44.

23. Ouzounian M, Hassan A, Buth KJ, et al. Impact of Endoscopic Versus Open Saphenous Vein Harvest Techniques on Outcomes After Coronary Artery Bypass Grafting. Ann Thorac Surg 2010;89:403-8.

24. Zenati MA, Shroyer AL, Collins JF, et al. Impact of endoscopic versus open saphenous vein harvest technique on late coronary artery bypass grafting patient outcomes in the ROOBY (Randomized On/Off Bypass) Trial. J Thorac Cardiovasc Surg 2011;141:338-44.

25. Ouzounian M, Ali IS. Endoscopic versus open saphenous vein harvest technique in the Randomized On/Off Bypass (ROOBY) Trial. J Thorac Cardiovasc Surg 2011;142:724-5.

26. Dacey LJ, Braxton JHJ, Kramer RS, et al. Long-term outcomes of endoscopic vein harvesting after coronary artery bypass grafting. Circulation 2011;123:147-53.

27. Williams JB, Peterson ED, Brennan JM, Sedrakyan A, Tavris D, Alexander JH, et al. Association between endoscopic vs open vein-graft harvesting and mortality, wound complications, and cardiovascular events in patients undergoing CABG surgery. JAMA. 2012;308:475-84.

28. Sastry P, Rivinius R, Harvey R, et al. The influence of endoscopic vein harvesting on outcomes after coronary bypass grafting: a meta-analysis of 267,525 patients. Eur J Cardiothorac Surg 2013;44:980-9.

29. Yun KL, Wu Y, Aharonian V, et al. Randomized trial of endoscopic versus open vein harvest for coronary artery bypass grafting: six-month patency rates. J Thorac Cardiovasc Surg 2005;129:496-503.

30. Andreasen JJ, Vadmann H, Oddershede L, et al. Decreased patency rates following endoscopic vein harvest in coronary artery bypass surgery. Scand Cardiovasc J 2015;49:286-92.

31. Antonopoulos AS, Odutayo A, Oikonomou EK, Trivella M, Petrou M, Collins GS, et al. Development of a risk score for early saphenous vein graft failure: An individual patient data meta-analysis. J Thorac Cardiovasc Surg 2020;160:116-127.e4.

32. Endoscopic saphenous vein harvest for coronary artery bypass grafting | Guidance and guidelines I NICE. [cited 2017 Jan 15]. Available online: https://www.nice.org.uk/ guidance/ipg494

33. Kodia K, Patel S, Weber MP, et al. Graft patency after open versus endoscopic saphenous vein harvest in coronary artery bypass grafting surgery: a systematic review and meta-analysis. Ann Cardiothorac Surg 2018;7:586-97.

34. Deppe AC, Liakopoulos OJ, Choi YH, et al. Endoscopic vein harvesting for coronary artery bypass grafting: a systematic review with meta-analysis of 27,789 patients. J Surg Res 2013;180:114-24.

35. Li G, Zhang Y, Wu Z, et al. Mid-term and long-term outcomes of endoscopic versus open vein harvesting for coronary artery bypass: A systematic review and metaanalysis. Int J Surg 2019;72:167-73.

36. Krishnamoorthy B, Critchley WR, Venkateswaran $\mathrm{RV}$, et al. A comprehensive review on learning curve associated problems in endoscopic vein harvesting and the requirement for a standardised training programme. J Cardiothorac Surg 2016;11:45.

37. Zenati MA, Bhatt DL, Bakaeen FG, et al. Randomized Trial of Endoscopic or Open Vein-Graft Harvesting for Coronary-Artery Bypass. N Engl J Med 2019;380:132-41.

38. Athanasiou T, Aziz O, Skapinakis P, et al. Leg wound infection after coronary artery bypass grafting: a metaanalysis comparing minimally invasive versus conventional vein harvesting. Ann Thorac Surg 2003;76:2141-6.

39. Luckraz H, Cartwright C, Nagarajan K, et al. Major adverse cardiac and cerebrovascular event and patients' quality of life after endoscopic vein harvesting as compared with open vein harvest (MAQEH): a pilot study. Open Heart 2018;5:e000694.

40. Allen KB, Shaar CJ. Facile location of the saphenous vein during endoscopic vessel harvesting. Ann Thorac Surg 2000;69:295-7.

41. Cohn JD, Korver KF. Optimizing saphenous vein site selection using intraoperative venous duplex ultrasound scanning. Ann Thorac Surg 2005;79:2013-7.

42. Illig KA, Rhodes JM, Sternbach Y, et al. Financial impact of endoscopic vein harvest for infrainguinal bypass. J Vasc Surg 2003;37:323-30.

43. Oddershede L, Andreasen JJ, Brocki BC, et al. Economic Evaluation of Endoscopic Versus Open Vein Harvest for Coronary Artery Bypass Grafting. Ann Thorac Surg 2012;93:1174-80.

44. Puskas JD, Wright CE, Miller PK, et al. A randomized trial of endoscopic versus open saphenous vein harvest in coronary bypass surgery. Ann Thorac Surg 1999;68:1509-12.

45. García-Altés A, Peiró S. A Systematic Review of Costeffectiveness Evidence of Endoscopic Saphenous Vein Harvesting: Is it Efficient? Eur J Vasc Endovasc Surg 2011;41:831-6.

46. Griffith GL, Allen KB, Waller BF, et al. Endoscopic 
and traditional saphenous vein harvest: a histologic comparison. Ann Thorac Surg 2000;69:520-3.

47. Bonde P, Graham A, MacGowan S. Endoscopic vein harvest: early results of a prospective trial with open vein harvest. Heart Surg Forum 2002;5 Suppl 4:S378-91.

48. Kiaii B, Moon BC, Massel D, et al. A prospective randomized trial of endoscopic versus conventional harvesting of the saphenous vein in coronary artery bypass surgery. J Thorac Cardiovasc Surg 2002;123:204-12.

49. Lamm P, Juchem G, Milz S, et al. Continuous graft perfusion: optimizing the quality of saphenous vein grafts. Heart Surg Forum 2002;5 Suppl 4:S355-61.

50. Krishnamoorthy B, Critchley WR, Thompson AJ, et al. Study Comparing Vein Integrity and Clinical Outcomes in Open Vein Harvesting and 2 Types of Endoscopic Vein Harvesting for Coronary Artery Bypass Grafting: The VICO Randomized Clinical Trial (Vein Integrity and Clinical Outcomes). Circulation 2017;136:1688-702.

51. Rousou LJ, Taylor KB, Lu XG, et al. Saphenous vein conduits harvested by endoscopic technique exhibit structural and functional damage. Ann Thorac Surg 2009;87:62-70.

52. Hussaini BE, Lu XG, Wolfe JA, et al. Evaluation of endoscopic vein extraction on structural and functional viability of saphenous vein endothelium. J Cardiothorac Surg 2011;6:82.

53. Desai $P$, Kiani S, Thiruvanthan N, et al. Impact of the learning curve for endoscopic vein harvest on conduit quality and early graft patency. Ann Thorac Surg 2011;91:1385-91; discussion 1391-2.

Cite this article as: Akowuah E, Burns D, Zacharias J, Kirmani BH. Endoscopic vein harvesting. J Thorac Dis 2021;13(3):18991908. doi: $10.21037 /$ jtd-20-1819
54. Hashmi SF, Krishnamoorthy B, Critchley WR, et al. Histological and immunohistochemical evaluation of human saphenous vein harvested by endoscopic and open conventional methods. Interact Cardiovasc Thorac Surg 2015;20:178-85.

55. Kim KB, Choi JW, Oh SJ, et al. Twenty-Year Experience With Off-Pump Coronary Artery Bypass Grafting and Early Postoperative Angiography. Ann Thorac Surg 2020;109:1112-9.

56. Dreifaldt M, Mannion JD, Bodin L, et al. The NoTouch Saphenous Vein as the Preferred Second Conduit for Coronary Artery Bypass Grafting. Ann Thorac Surg 2013;96:105-11.

57. Samano N, Geijer H, Liden M, et al. The no-touch saphenous vein for coronary artery bypass grafting maintains a patency, after 16 years, comparable to the left internal thoracic artery: A randomized trial. J Thorac Cardiovasc Surg 2015;150:880-8.

58. Samano N, Souza D, Pinheiro BB, et al. Twenty-Five Years of No-Touch Saphenous Vein Harvesting for Coronary Artery Bypass Grafting: Structural Observations and Impact on Graft Performance. Braz J Cardiovasc Surg 2020;35:91-9.

59. Waheed A, Klosterman E, Lee J, et al. Assessing the Long-term Patency and Clinical Outcomes of Venous and Arterial Grafts Used in Coronary Artery Bypass Grafting: A Meta-analysis. Cureus 2019;11:e5670.

60. Neumann FJ, Sousa-Uva M, Ahlsson A, et al. 2018 ESC/ EACTS Guidelines on myocardial revascularization. Eur Heart J 2019;40:87-165. 